\title{
Influence of Cinnamon Bark Powder on Hyperglycemic Rats
}

\author{
Esmail G. Boriy
}

\author{
Food Sciences and Technology Department, Faculty of Agriculture, Damanhur University, Egypt.
}

Received: 07 Oct. 2019 / Accepted 10 Dec. 2019/ Publication date: 30 Dec. 2019

\begin{abstract}
The goal of this work was to study the influence of cinnamon bark powder (CBP) on blood sugar in diabetic rats. The results of chemical analyzes of CBP were found to be a high source of antioxidants, dietary fiber, phenolic or flavonoid components like coumarin, chlorogenic acid, gallic acid and vanillic acid. Ferulic acid, syringic acid, cinnamic acid, caffeine, caffeic acid, catechin and catechol. These compounds are effective in lowering blood sugar levels. The results revealed that CBP could be added to substitute to 3,6 and 9\% of hyperglycemic -diet respectively. Experimental hyperglycemic rats were fed for six weeks on diet contain CBP at level 3, 6 and 9\% except normal control (G1) was fed on basal diet. The found that Diabetic animals fed on diets substituted in a part with 3,6 and 9\% CBP the results indicated that supplementing the hyperglycemic-producing diets with the additive CBP The results indicate that cinnamon reduces the level of sugar and harmful fats and improves liver and kidney function in the affected rats compared to the control.
\end{abstract}

Keywords: Cinnamon, bark, flavonoids, fibre, diabetes, rats

\section{Introduction}

Cinnamon comes from the inner bark of evergreen tropical cinnamon trees, and is derived from a Greek term meaning sweet wood. (Vinitha and Ballal, 2008). Cinnamomum (cinnamon) is a Lauraceae genus with a large number of members used as spices (Shan and Brooks, 2007). It is one of the most extensively used flavouring compounds in the food and beverage sector, and its therapeutic effects have been known since antiquity. Cinnamon extracts have long been used in Ayurvedic medicine to treat diseases like arthritis, diarrhoea, and menstrual irregularities. (Medagama and Bandara, 2014). There are around 250 species of cinnamon known to date, four of which are utilised to make the spice cinnamon. Cinnamomum verum (syn C. zeylanicum), sometimes known as true or Ceylon cinnamon, is a tiny evergreen tree native to Sri Lanka. The other most generally available species is Chinese cassia cinnamon Cinnamomum cassia (Jayaprakasha and Rao, 2011).

Dietary fiber (DF) is defined as "an edible component of carbohydrates or similar plants that resists digestion and absorption in the human small intestine, with partial or complete fermentation in the large intestine." (AACC, 2001; Westenbrink et al., 2013). A large number of scientific studies have found that DF is linked to a lower risk of chronic diseases. Previous research has shown that increasing DF intake can help with cardiovascular disease, diabetes, and certain cancers, including colon cancer, as well as constipation. (Bosaeus, 2004; Kaczmarczyk et al., 2012). As a result, DF is widely acknowledged as one of the most significant components of a health-promoting diet. Consumer awareness of the benefits of DF-enriched foods has grown in recent decades, as consumers seek to better their health and quality of life. In order to meet increased consumer demand for DF-rich foods, the food sector is constantly working to improve product quality. (Ballali and Lanciai, 2012) As a result, a variety of health-promoting goods have appeared on the market. Cereals like oat, wheat, and corn have traditionally been utilised to boost the DF content in dishes. (McKee and Latner, 2000).

Synthesis and transport of glucose transporter 4 (GLUT-4) receptors, modulation of hepatic glucose metabolism through changes in pyruvate kinase (PK) and phosphenol pyruvate carboxykinase (PEPCK), alteration of expression of PPAR $\gamma(0)$, and inhibition of intestinal glucosides. Mechanisms responsible for improving blood sugar. We looked at eight clinical trials that utilised Cinnamomum cassia in aqueous or powder form in doses ranging from $500 \mathrm{mg}$ to six gram per day for forty days to four months, as well as two trials that used cinnamon on treatment-naive pre-diabetic patients. Patients who took Cinnamon as their sole diabetes treatment, those with pre-diabetes (IFG or IGT), and those with high pre-treatment $\mathrm{HbAlc}$ all improved their glycaemic control. Cinnamon lowered fasting and postprandial plasma glucose, as well as HbA1c, in animal studies. Medagama, (2015).

Corresponding Author: Esmail G. Boriy, Food Sciences and Technology Department, Faculty of Agriculture, Damanhur University, Egypt. 
Many thousands of bioactive chemicals make up a plant, and isolating them can be difficult and time-consuming. Jayaprakasha et al., (2011), the volatile oils of Cinnamon present in the leaves and bark were isolated using hydro-distillation processes. Eugenol, cinnamaldehyde, copane, cinnamyl acetate, and camphor, as well as minor components, were discovered (Jayaprakasha and Rao, 2011). Cinnamaldehyde, cinnamyl acetate, and camphor have all been obtained from the bark by previous researchers. Cinnamon's active component, which has hypoglycaemic properties, is a disputed topic (Anderson et al., 2015). Therefore the goal of this reaserch was to study the influence of (CBP) on serum glucose, TC, TL, TGL, HDL-C, LDL-C, ALT, AST, urea and creatinine in hyperglcemic rats.

\section{Materials and Methods}

\section{Materials}

Proximate analyses were conducted using AOAC (1996) for crude fibre, ash (dry-ashing method), crude protein by nitrogen conversion factor of 6.25 (Kjeldahl method) and ether extract using the semi continuous extraction (Soxhlet method).

Total dietary fibre (TDF) of CBP was determined by enzymatic gravimetric method, based on the method of AOAC 985.29 and AACC 32-05. Insoluble dietary fibre (IDF) and soluble dietary fibre (SDF) of the samples were determined according to AOAC 991.42, 993.19 and AACC 32-21.

\section{Determination of phenolic and flavonoids compounds}

Phenolic compounds were fractionated and identified by High Performance Liquid Chromatography (HPLC), Hewllet Packard, series1050 according to the method of Goupy et al., (1999). Flavonoids compounds were determined according to Mattila et al., (2000).

\section{Rats feeding}

Total of thirty rats of adult male albino rats of weighted (165.38) were used in current experiment in the animal house of food Technology. Research. Institute, Agric, Res., Center, Giza, Egypt, under normal healthy conditions for 10 days and fed on a normal diet (basal diet) as shown Table 1 which containing salt mixture (4\%), vitamin mixture $1 \%$. The rats were allowed free access of tap water and were fed on uniformly based diet.

Table 1: Composition of the basal diet.

\begin{tabular}{lccc}
\hline Ingredient & $\mathbf{g} / \mathbf{1 0 0 g}$ diet & Ingredient & g/100g diet \\
\hline Corn starch & 60 & Cellulose & 5 \\
Corn oil & 10 & Salt mixture & 4 \\
Casein & 20 & Vitamin mixture & 1 \\
\hline
\end{tabular}

(Lane-Peter and Pearson, 1971)

\section{Design of experiment}

After feeding on the basic diet for ten days (adjustment period). Six mice were kept as a control group (G1), which were fed basic feed during the experiment period. Diabetes was induced in 24 rats as described (Dawson et al., 1986) as follows: overnight fasted rats were injected intraperitoneal by streptozotocin (STZ) at dose $60 \mathrm{mg} / \mathrm{kg}$ b wt. After 3 days of injection (zero time), blood samples were taken from each rat for the determination of serum glucose to ensure the occurrence of diabetes. Animals with serum glucose levels of $250-550 \mathrm{mg} / 100 \mathrm{ml}$ were considered as diabetic rats.

\section{Hyperglycemia experiment of cinnamon}

G1: Fed on the basic diet (negative control).

G2: Fed on the basic diet (Positive diabetic control).

G3: Fed on the basic diet with 3\% Cinnamon powder.

G4: Fed on the basic diet with $6 \%$ Cinnamon powder.

G5: Fed on the basic diet with $9 \%$ Cinnamon powder. 
At the end of the experiment ( 6 weeks) each animal was anesthetized with ethyl ether. Blood was collected from the eye of the venous plexus and placed in a dry, clean place by centrifugation for 10 min at $3000 \mathrm{rpm}$ to separate serum, which was frozen at $-20{ }^{\circ} \mathrm{C}$ in dry, clean plastic until analysis.

\section{Biochemical analysis}

Serum glucose, cholesterol (CHL), low density lipoprotein (LDL), high density lipoprotein (HDL), triglyceride (TG), serum alanine amino-transferase (ALT), serum aspartate amino-transferase (AST), alkaline phosphatase (ALP), albumin (ALB), urea, creatinine, uric acid, purchased from SPINREACT Co, SPAIN 2019.

\section{Statistical evaluation}

The obtained results were analyzed statistically using Analysis of Variance (One way ANOVA) using SPSS 16.0

\section{Results and Discussion}

\subsection{The chemical composition of CBP}

Results obtainable in Table 2 showed that CBP content of $3.55 \%$ for ether extract, $8.37 \%$ for protein, $4.50 \%$ for ash, $25.70 \%$ for crude fibre, $45.38 \%$ for total dietary fibre, 10.80 for soluble dietary fibre and $34.58 \%$ for Insoluble dietary fibre, respectively.

Table 2: Chemical composition of CBP.

\begin{tabular}{ll}
\hline Components & CBP \% \\
\hline Ether extract\% & 3.55 \\
Ash\% & 4.50 \\
Crude protein\% & 8.37 \\
Crude fibre\% & 25.70 \\
Total dietary fibre\% & 45.38 \\
Soluble dietary fibre\% & 10.80 \\
Insoluble dietary fibre\% & 34.58 \\
\hline Phenolic compounds & $\mathbf{( m g / 1 0 0 ~ g ~ d r y ~ w e i g h t ) ~}$ \\
Cinnamic acid & 2.55 \\
Caffeic acid & 0.65 \\
Coumarin & 530 \\
Vanillic acid & 4.40 \\
Syringic acid & 0.45 \\
Salicylic acid & 19.0 \\
Cholorgenic acid & 0.25 \\
Ferulic acid & 1.80 \\
P-Coumaric acid & 0.19 \\
P-Hydroxybenzoic acid & 3.60 \\
Catechol & 0.54 \\
3,4Dihdroxybenzaldehyde & 15.5 \\
\hline Flavonoids Components & $\mathbf{( m g / 1 0 0} \mathbf{g}$ dry weight) \\
Catechin & 2.30 \\
Rutin & 0.75 \\
Quercetin & 0.60 \\
Isorhamentin & 0.20 \\
Caffeiene & 0.95 \\
Kaempferol & 0.59 \\
\hline
\end{tabular}

These results are similar to Elhadidy (2009) who reported that CBP contains $10.79 \%$ ether extract, 4.64\% ash, $7.13 \%$ crude protein and $19.53 \%$ crude fiber. Also $\mathrm{Ng}$ and Wan (2014) showed that cinnamon contain $48.38 \%$ total dietary fiber, 10.80 for soluble dietary fiber, $37.50 \%$ for Insoluble dietary fiber and $6.31 \%$ crude protein.

Cinnamon's phenolic components were isolated and identified using High Performance Liquid Chromatography (HPLC).The data are showed in Table 2. Twelve phenolic compounds have been 
identified coumarin has been accepted as a main compound in cinnamon powder ( $530 \mathrm{mg} / 100 \mathrm{~g})$, salicylic acid $(19.00 \mathrm{mg} / 100 \mathrm{~g}), 3,4$ Dihdroxybenzaldehyde $(15.50 \mathrm{mg} / 100 \mathrm{~g})$, vanillic acid $(4.40 \mathrm{mg} / 100 \mathrm{~g})$, cinnamic acid $(2.55 \mathrm{mg} / 100 \mathrm{~g})$, caffeic acid and ferulic acid. Meanwhile, catechin $(2.30 \mathrm{mg} / 100 \mathrm{~g})$, caffeiene $(0.95 \mathrm{mg} / 100 \mathrm{~g})$ and rutin $(0.75 \mathrm{mg} / 100 \mathrm{~g})$ for flavonoids compounds. These results are similar to Elhadidy (2009) who reported that CBP extract contain higher amounts of coumarin, cholorgenic acid, gallic acid and vanillic. Followed by ferrulic acid, cinnamic acid, caffeine, caffeic acid, syringic acid, catechein and catechol.

\subsection{Influence of feeding different CBP on body weight of diabetic rats}

Table 3 shows the effect of adding CBP to the basic diet on the weights of diabetic rats compared to the (negative control) and (positive control) groups. It was observed that there was an improvement in the weights of rats fed the basic diet with CBP compared to the (positive diabetes control) groups, and the improvement increased by increasing the concentration of $\mathrm{CBP}$ added to the basic feed.

Table 3: Influence of feeding different CBP on body weight of diabetic rats.

\begin{tabular}{cccc}
\hline Groups of rats & $\begin{array}{c}\text { Initial weight } \\
(\mathbf{g})(\mathbf{M} \pm \mathbf{S D})\end{array}$ & $\begin{array}{c}\text { Final weight } \\
(\mathbf{g})(\mathbf{M} \pm \mathbf{S D})\end{array}$ & $\begin{array}{c}\text { Change in body weight } \\
(\mathbf{g})(\mathbf{M} \pm \mathbf{S D})\end{array}$ \\
\hline $\mathbf{G 1}$ & $165.56^{\mathrm{a}} \pm 1.67$ & $188.76^{\mathrm{a}} \pm 1.75$ & $23.20^{\mathrm{a}} \pm 2.08$ \\
$\mathbf{G 2}$ & $163.56^{\mathrm{a}} \pm 1.90$ & $154.68^{\mathrm{d}} \pm 1.95$ & $-8.88^{\mathrm{c}} \pm 0.33$ \\
$\mathbf{G 3}$ & $164.09^{\mathrm{a}} \pm 1.76$ & $181.86^{\mathrm{c}} \pm 2.06$ & $17.77^{\mathrm{b}} \pm 1.20$ \\
$\mathbf{G 4}$ & $167.23^{\mathrm{a}} \pm 2.05$ & $181.65^{\mathrm{c}} \pm 2.29$ & $16.42^{\mathrm{b}} \pm 0.88$ \\
$\mathbf{G 5}$ & $166.45^{\mathrm{a}} \pm 2.58$ & $188.67^{\mathrm{b}} \pm 2.21$ & $22.22^{\mathrm{a}} \pm 0.33$ \\
\hline
\end{tabular}

Each value is an average of six determinations.

Values followed by the same letter in column are not significantly different at $\mathrm{p} \leq 0.05$.

\subsection{Influence of feeding on different CBP on blood glucose level of diabetic rats}

Table 4 shows the influence of adding CBP to the basic diet on the glucose level in diabetic rats compared to the (negative control) and (positive control) groups. A decrease in sugar level was observed in rats fed the basic feed with CBP compared to the (positive diabetes control) groups, and the decrease in blood glucose content increased with the increase in the concentration of CBP added to the basic feed.

Table 4: Influence of feeding on different CBP on blood glucose level of diabetic rats.

\begin{tabular}{ccccc}
$\begin{array}{c}\text { Rat } \\
\text { groups }\end{array}$ & $\begin{array}{c}\text { After 3 days }(\mathbf{m g} / \mathbf{d l}) \\
(\mathbf{M} \pm \mathbf{S D})\end{array}$ & $\begin{array}{c}\text { After2 weeks } \\
(\mathbf{m g} / \mathbf{d l})(\mathbf{M} \pm \mathbf{S D})\end{array}$ & $\begin{array}{c}\text { After 4 weeks } \\
(\mathbf{m g} / \mathbf{d l})(\mathbf{M} \pm \mathbf{S D})\end{array}$ & $\begin{array}{c}\text { After 6 weeks } \\
(\mathbf{m g} / \mathbf{d l})(\mathbf{M} \pm \mathbf{S D})\end{array}$ \\
\hline G1 & $104.32^{\mathrm{b}} \pm 2.44$ & $102.32^{\mathrm{e}} \pm 3.58$ & $101.98^{\mathrm{e}} \pm 2.17$ & $98.68^{\mathrm{e}} \pm 1.53$ \\
G2 & $307.65^{\mathrm{a}} \pm 3.31$ & $314.23^{\mathrm{a}} \pm 2.88$ & $322.33^{\mathrm{a}} \pm 3.85$ & $325.57^{\mathrm{a}} \pm 1.47$ \\
G3 & $308.22^{\mathrm{a}} \pm 3.46$ & $288.35^{\mathrm{b}} \pm 3.45$ & $244.00^{\mathrm{b}} \pm 2.75$ & $222.54^{\mathrm{b}} \pm 1.45$ \\
G4 & $309.11^{\mathrm{a}} \pm 4.37$ & $274.43^{\mathrm{c}} \pm 2.67$ & $209.00^{\mathrm{c}} \pm 3.65$ & $170.63^{\mathrm{c}} \pm 2.23$ \\
G5 & $306.92^{\mathrm{a}} \pm 3.43$ & $265.34^{\mathrm{d}} \pm 3.08$ & $194.00^{\mathrm{d}} \pm 5.42$ & $153.53^{\mathrm{d}} \pm 2.53$ \\
\hline
\end{tabular}

Each value is an average of six determinations.

Values followed by the same letter in column are not significantly different at $p \leq 0.05$.

\subsection{Influence of feeding different CBP on lipids serum parameters of diabetic rats:-}

It was found that high blood sugar level may lead to high level of lipid profile. Table 5 showed the effect of adding CBP to the basic diet on the level of lipids in diabetic rats compared to the (negative control) and (positive control) groups. The table shows the low level of harmful fats (TC.LDLC.VLDL-C and Triglycerides) and the high level of beneficial fats (HDL-C) in the groups fed with $\mathrm{CBP}$, and that the blood lipids decrease with the increase in the extent of CBP.

\subsection{Influence of feeding different CBP on liver functions of diabetic rats}

Research indicates that high blood sugar level negatively affects liver function. Table 6 indicates the effect of adding CBP to the diet of diabetic rats on liver function. The results indicate an improvement in liver function in mice fed CBP compared to the control. 
Table 5: Influence of feeding different $\mathrm{CBP}$ on lipids serum parameters of diabetic rats.

\begin{tabular}{cccccc}
\hline $\begin{array}{c}\text { Rat } \\
\text { groups }\end{array}$ & $\begin{array}{c}\mathbf{T C}(\mathbf{m g} / \mathbf{d l}) \\
\mathbf{( M} \pm \mathbf{S D})\end{array}$ & $\begin{array}{c}\text { HDL-C } \\
\mathbf{( m g / d l )} \\
(\mathbf{M} \pm \mathbf{S D})\end{array}$ & $\begin{array}{c}\text { LDL-C } \\
\mathbf{( m g} / \mathbf{d l}) \\
\mathbf{( M} \pm \mathbf{S D})\end{array}$ & $\begin{array}{c}\text { Triglycerides } \\
(\mathbf{m g} / \mathbf{d l}) \\
(\mathbf{M} \pm \mathbf{S D})\end{array}$ & $\begin{array}{c}\text { VLDL } \\
(\mathbf{m g} / \mathbf{d l}) \\
(\mathbf{M} \pm \mathbf{S D})\end{array}$ \\
\hline $\mathbf{G 1}$ & $119.86^{\mathrm{e}} \pm 1.42$ & $71.04^{\mathrm{a}} \pm 2.45$ & $23.88^{\mathrm{e}} \pm 2.32$ & $124.70^{\mathrm{e}} \pm 2.16$ & $24.94^{\mathrm{e}} \pm 1.91$ \\
$\mathbf{G 2}$ & $162.84^{\mathrm{a}} \pm 1.22$ & $36.00^{\mathrm{e}} \pm 2.32$ & $86.91^{\mathrm{a}} \pm 2.52$ & $199.65^{\mathrm{a}} \pm 2.42$ & $39.93^{\mathrm{a}} \pm 2.1$ \\
$\mathbf{G 3}$ & $142.18^{\mathrm{b}} \pm 1.33$ & $45.06^{\mathrm{d}} \pm 2.26$ & $66.20^{\mathrm{b}} \pm 1.96$ & $154.60^{\mathrm{b}} \pm 2.73$ & $30.92^{\mathrm{b}} \pm 2.4$ \\
$\mathbf{G 4}$ & $132.87^{\mathrm{c}} \pm 2.26$ & $48.99^{\mathrm{c}} \pm 2.51$ & $55.45^{\mathrm{c}} \pm 2.73$ & $142.15^{\mathrm{c}} \pm 2.35$ & $28.43^{\mathrm{c}} \pm 2.41$ \\
$\mathbf{G 5}$ & $131.19^{\mathrm{d}} \pm 1.45$ & $52.55^{\mathrm{b}} \pm 1.98$ & $51.02^{\mathrm{d}} \pm 2.12$ & $138.10^{\mathrm{d}} \pm 2.63$ & $27.62^{\mathrm{d}} \pm 2.61$ \\
\hline
\end{tabular}

$\mathrm{TC}=$ Total cholesterol, HDL-C $=$ High density lipoprotein cholesterol, LDL-C $=$ Low density lipoprotein cholesterol Each value is an average of six determinations.

Values followed by the same letter in column are not significantly different at $\mathrm{p} \leq 0.05$.

Table 6: Influence of feeding different CBP on liver functions of diabetic rats.

\begin{tabular}{cccc}
\hline $\begin{array}{c}\text { Rat } \\
\text { groups }\end{array}$ & $\begin{array}{c}\text { GOT } \\
(\mathbf{A S T}) \mathbf{I U} / \mathbf{L}(\mathbf{M} \pm \mathbf{S D})\end{array}$ & $\begin{array}{c}\text { GPT } \\
\text { (ALT) } \mathbf{I U} / \mathbf{L}(\mathbf{M} \pm \mathbf{S D})\end{array}$ & $\begin{array}{c}\text { Albumin } \\
(\mathbf{m g} / \mathbf{d l}){ }^{*}(\mathbf{M} \pm \mathbf{S D})\end{array}$ \\
\hline $\mathbf{G 1}$ & $35.31^{\mathrm{b}} \pm 4.18$ & $33.54^{\mathrm{b}} \pm 2.36$ & $3.72^{\mathrm{d}} \pm 1.35$ \\
G2 & $46.11^{\mathrm{a}} \pm 3.24$ & $42.53^{\mathrm{a}} \pm 3.68$ & $6.55^{\mathrm{a}} \pm 2.53$ \\
$\mathbf{G 3}$ & $35.34^{\mathrm{b}} \pm 3.31$ & $37.67^{\mathrm{ab}} \pm 4.65$ & $4.86^{\mathrm{b}} \pm 1.36$ \\
$\mathbf{G 4}$ & $34.35^{\mathrm{b}} \pm 2.46$ & $36.13^{\mathrm{ab}} \pm 3.32$ & $4.27^{\mathrm{b}} \pm 3.53$ \\
$\mathbf{G 5}$ & $33.12^{\mathrm{b}} \pm 3.52$ & $34.43^{\mathrm{b}} \pm 2.28$ & $4.12^{\mathrm{c}} \pm 2.44$ \\
\hline
\end{tabular}

Each value is an average of six determinations.

Values followed by the same letter in column are not significantly different at $\mathrm{p} \leq 0.05$.

\subsection{Influence of feeding different CBP on kidney functions of diabetic rats:}

Research indicates that high blood glucose level negatively affects kidney function. Table 7 indicates the effect of adding CBP to the diet of diabetic rats on kidney function. The results indicate an improvement in kidney function in rats fed on CBP compared to the control

Table 7: Influence of feeding at different CBP on kidney functions of diabetic rats.

\begin{tabular}{cccc}
\hline $\begin{array}{c}\text { Rat } \\
\text { groups }\end{array}$ & $\begin{array}{c}\text { Urea } \\
(\mathbf{~ m g} / \mathbf{d l})^{*}(\mathbf{M} \pm \mathbf{S D})\end{array}$ & $\begin{array}{c}\text { Creatinine } \\
(\mathbf{m g} / \mathbf{d l}) *(\mathbf{M} \pm \mathbf{S D})\end{array}$ & $\begin{array}{c}\text { Uric acid } \\
(\mathbf{m g} / \mathbf{d l}) * \mathbf{M} \pm \mathbf{S D})\end{array}$ \\
\hline $\mathbf{G 1}$ & $37.19^{\mathrm{b}} \pm 2.15$ & $0.74^{\mathrm{c}} \pm 0.13$ & $3.43^{\mathrm{ab}} \pm 0.53$ \\
$\mathbf{G 2}$ & $47.53^{\mathrm{a}} \pm 3.13$ & $1.47^{\mathrm{a}} \pm 0.12$ & $4.77^{\mathrm{a}} \pm 0.78$ \\
$\mathbf{G 3}$ & $38.87^{\mathrm{b}} \pm 4.23$ & $0.89^{\mathrm{b}} \pm 0.23$ & $4.10^{\mathrm{b}} \pm 0.67$ \\
$\mathbf{G 4}$ & $37.87^{\mathrm{b}} \pm 3.13$ & $0.87^{\mathrm{b}} \pm 0.17$ & $3.77^{\mathrm{ab}} \pm 0.57$ \\
$\mathbf{G 5}$ & $35.20^{\mathrm{b}} \pm 3.87$ & $0.84^{\mathrm{b}} \pm 0.13$ & $3.69^{\mathrm{ab}} \pm 0.36$ \\
\hline
\end{tabular}

Each value is an average of six determinations.

Values followed by the same letter in column are not significantly different at $\mathrm{p} \leq 0.05$.

Influence of feeding different on CBP organs weight of rats of diabetic rats:

The results in Table 8 indicate that there is a decrease in the weight of the organs of diabetic rats fed with CBP compared to the control, which indicates that CBP has an effective role on the organs of the body.

Table 8: Influence of feeding different CBP on organs weight of rats of diabetic rats.

\begin{tabular}{ccccc}
\hline $\begin{array}{c}\text { Rat } \\
\text { Groups }\end{array}$ & Spleen(g) & Heart(g) & Kidney $(g)$ & Liver(g) \\
\hline G1 & $0.74^{\mathrm{c}} \pm 0.27$ & $0.62^{\mathrm{c}} \pm 0.23$ & $1.34^{\mathrm{d}} \pm 0.33$ & $7.43^{\mathrm{bc}} \pm 0.22$ \\
G2 & $0.92^{\mathrm{a}} \pm 0.22$ & $0.81^{\mathrm{a}} \pm 0.35$ & $1.85^{\mathrm{a}} \pm 0.34$ & $9.76^{\mathrm{a}} \pm 0.43$ \\
G3 & $0.90^{\mathrm{ab}} \pm 0.37$ & $0.71^{\mathrm{ab}} \pm 0.23$ & $1.82^{\mathrm{a}} \pm 0.13$ & $8.69^{\mathrm{ab}} \pm 0.55$ \\
G4 & $0.83^{\mathrm{b}} \pm 0.23$ & $0.69^{\mathrm{b}} \pm 0.45$ & $1.72^{\mathrm{b}} \pm 0.25$ & $7.75^{\mathrm{abc}} \pm 0.63$ \\
G5 & $0.66^{\mathrm{cd}} \pm 0.31$ & $0.65^{\mathrm{b}} \pm 0.34$ & $1.42^{\mathrm{c}} \pm 0.14$ & $7.49^{\mathrm{bc}} \pm 0.52$ \\
\hline
\end{tabular}

Each value is an average of six determinations.

Values followed by the same letter in column are not significantly different at $\mathrm{p} \leq 0.05$. 


\section{Discussion}

Streptozotocin STZ [2-deoxy-2-3(3-methyl-3-nitrosoureido)-D-glucopyra nose] is commonly used for the induction of experimental diabetes in animals (Al-Attar and Zari, 2007). Streptozotocin has the ability to act as an intracellular nitric oxide (NO) donor and to generate reactive oxygen species (ROS). The synergistic action of NO and ROS may also contribute to DNA fragmentation and other detrimental changes induced by streptozotocin (Lenzen, 2008). On the other hand, cinnamon prevents the development of insulin resistance, at least in part by enhancing insulin signaling and possibly via the NO pathway in skeletal muscle (Qin et al., 2010a). In addition, another study confirms that cinnamon increases glucose uptake and GLUT4 (glucose transporter) expression in 3T3-L1 fat cells. Cinnamon aqueous extract (Cinnulin PF) was revealed to reduce blood glucose and soluble CD36 (CD36), which has been reported as a new marker of insulin resistance (Qin et al., 2010b). In another study, cinnamon lowers blood glucose through several mechanisms such as reducing intestinal glucose uptake, stimulating cellular glucose uptake, glycogen synthesis, insulin release, potentiation of insulin receptor activity, and inhibition of gluconeogenesis (Ranasinghe et al., 2013). Similarly, cinnamon bark extracts have been found useful for controlling glucose uptake in diabetic patients through inhibition of the intestinal enzyme a-glucosidase and pancreatic amylase ( Kongstad et al., 2015).

Cinnamon reduced fasting glucose levels in severely obese, insulin-resistant mice using cinnamon extract supplementation for 6 weeks. The previous model shows a decrease in liver triglyceride content and an increase in glycogen concentration along with improved insulin sensitivity in the liver (Bitencourt et al., 2015).

Elevated levels of SGPT, SGOT, urea and creatinine were observed in streptozotocin-infected mice. This behavior indicates liver and kidney damage after administration of streptozotocin to mice. Others have attributed these rises to streptozotocin-induced liver damage, which may cause the above enzymes to leak into the blood (Calisti and Tognetti, 2005). Persistent hyperglycemia, changes in blood circulation within the kidney tissues and generation of free radicals mediated by impaired renal function, resulting in elevated serum urea and creatinine levels (Shokeen et al., 2008). Cinnamon for diabetic rats mainly reduced the levels of SGOT, SGPT, creatinine and urea, indicating the protective effect of cinnamon on liver and kidney damage in the diabetic condition. Cinnamon attenuates diabetic kidney dysfunction in rats as indicated by decreased urinary albumin and creatinine (Muthenna et al., 2014).

Another study revealed the use of cinnamon as a medicinal plant for kidney and liver diseases (Saganuwan, 2010). In the case of diabetes, increased TC and TG levels and decreased HDL levels along with altered composition of LDL particles have been commonly reported (Howard et al., 2000). The previous study is consistent with our study after administration of STZ that altered normal lipid profiles. The levels of TC, TG, LDL, and VLDL were increased while the level of HDL appeared to be decreased when compared to normal mice. The same results were shown in diabetic rats fed on a highfat diet by (Sharma et al., 2012). These lipid forms have been recycled to stabilize at normal levels after treatment with cinnamon. This lipid-lowering action may be due to the appropriate stabilization of glucose and the increase in insulin level after administration of cinnamon which may lead to the normalization of the disturbed lipid metabolism in diabetic mice. Cinnamon may inhibit HMG-CoA reductase (3-hydroxy-3-methyl-glutaryl-CoA reductase) indicating a low level of TC (Sartorius et al., 2014). Therefore, the hypolipidemic effect of cinnamon in diabetic rats supports its ability to prevent diabetes-related cardiovascular disease. A decrease in the triglyceride content in the liver accompanied by an increase in glycogen storage was observed by eating cinnamon (Sartorius et al., 2014).

Currently, antioxidants are proposed as a primary mechanism of diabetes mellitus and its complications. Foods of plant origin such as cinnamon have been reported to contain anthocyanins, cyanidins, tannins, vitamin C, gallic acid, glucoside, malvidin, and petonidine, which have antioxidant activity (Rupasinghe et al., 2003). Possibly the phenolic components of cinnamon are responsible for the free radical scavenging and antioxidant activity (Im et al., 2014).

\section{In Conclusion}

The current study indicates that the cinnamon treatment had an ideal effect not only as an antihyperglycemic, but also on the level of lipids, improving liver and kidney function, and as a powerful antioxidant. These results indicate the promising effect of cinnamon as collaborators specialized in the 
treatment of diabetes, and the prevention of any diabetes, whose therapeutic efficacy can only be envisaged after clinical trials.

\section{References}

AACC., 2001. The definition of dietary fiber. (Report of the Dietary Fiber Definition Committee to the Board of Directors of AACC). Cereal Foods World 46(3): 112-126.

Al-Attar, A.M., and T.A. Zari, 2007. Modulatory effect of ginger and clove oil on physiological response in streptozotocin-induced diabetic rats. Int. J. Pharmacol., 3, 34-40.

Anderson, R.A., Z. Zhan, R. Luo, X. Guo, Q. Guo, J. Zhou, J. Kong, P.A. Davis, and B.J. Stoecker, 2015. Cinnamon extract lowers glucose, insulin and cholesterol in people with elevated serum glucose. J Tradit Compl Med., doi: 10.1016/j.jtcme.201503.005

AOAC., 1996. Official Methods of Analysis of AOAC International (16th ed.). AOAC International Suite 500, Maryland USA.

Ballali, S., and F. Lanciai, 2012. Functional food and diabetes: a natural way in diabetes prevention? International Journal of Food Sciences and Nutrition, 63(1): 51-61.

Bitencourt, P.E., K.S. Bona, L.O. Cargnelutti, G. Bonfanti, A. Pigatto, A. Boligon, M.L. Athayde, F. Pierezan, R.A. Zanette, M.B. Moretto, 2015. Syzygium cumini seed extract ameliorates adenosine deaminase activity and biochemical parameters but does not alter insulin sensitivity and pancreas architecture in a shortterm model of diabetes. J. Complement. Integr. Med., 12: 5187- 5193.

Bosaeus, I., 2004. Fibre effects on intestinal functions (diarrhoea, constipation and irritable bowel syndrome). Clinical Nutrition Supplements, 1(2): 33-38.

Calisti, L., and S. Tognetti, 2005. Measure of glycosylated hemoglobin. Acta Biomed. 76 (Suppl. 3): $59-62$.

Dawson, R.M.C., D.C. Elliott, W.H. Elliott, and K.M. Jones, 1986 Data for Biochemical Research, 3rd edition, Oxford: Calderon Press.

Elhadiy. G.S., 2009. Chemical and Biological Studies on Some Hypoglycemic Foods. M. Sc. Thesis, Fac. of Agric. Food technology Dep., Tanta Univ., Egypt.

Goupy, P.H., P. Boivin, and M. Amiot, 1999. Antioxidant composition and activity of barley (Hordeum vulgare) and malt extracts and of isolated phenolic compounds. J. Sci. Food and Agric., 79: 16251634.

Howard, B.V., D.C. Robbins, M.L. Sievers, E.T. Lee, D. Rhoades, R.B. Devereux, L.D. Cowan, R.S. Gray, T.K. Welty, O.T. Go, and W.J. Howard, 2000. LDL cholesterol as a strong predictor of coronary heart disease in diabetic individuals with insulin resistance and low LDL: the strong heart study. Arterioscler. Thromb. Vasc. Biol., 20: 830-835.

Jayaprakasha, G.K. and L.J. Rao, 2011. Chemistry, biogenesis, and biological activities of Cinnamomum zeylanicum. Crit Rev Food Sci. Nutr., 51(6):547-62

Jayaprakasha, G.K. and L.J. Rao, 2011. Chemistry, biogenesis, and biological activities of Cinnamomum zeylanicum. Crit Rev Food Sci. Nutr., 51(6):547-62.

Kaczmarczyk, M.M., M.J. Miller, and G.G. Freund, 2012. The health benefits of dietary fiber: Beyond the usual suspects of type 2 diabetes mellitus, cardiovascular disease and colon cancer. Metabolism, 61(8): 1058- 1066

Kongstad, K.T., C. Ozdemir, A. Barzak, S.G. Wubshet, and D. Staerk, 2015. Combined use of highresolution alpha-glucosidase inhibition profiling and high-performance liquid chromatographyhigh-resolution mass spectrometry-solid-phase extraction-nuclear magnetic resonance spectroscopy for investigation of antidiabetic principles in crude plant extracts. J. Agric. Food Chem., 63: 2257-2263.

Lane-peter, W. and A.E. Pearson, 1971. Dietary requirement in "the laboratory animal principals and practice" p142, Academic press, London and New York.

Lenzen, S., 2008. The mechanisms of alloxan- and streptozotocininduced diabetes. Diabetologia, 51: 216-226.

Mattila, P., J. Astola, and J. Kumpulainen, 2000. Determination of flavonoids in plant material by HPLC with diode-array and electro-array detections. J. Agric. Food Chem., 48: 5834-5841.

McKee, L.H. and T.A. Latner, 2000. Underutilized sources of dietary fiber: A review. Plant Foods for Human Nutrition, 55(4): 285-304. 
Medagama, A.B., 2015. The glycaemic outcomes of Cinnamon, a review of the experimental evidence and clinical trials, Journal Nutrition Journal (2015) 14:108. DOI 10.1186/s12937-015-0098-9

Medagama, A.B. and R. Bandara, 2014. The use of Complementary and Alternative Medicines (CAMs) in the treatment of diabetes mellitus: is continued use safe and effective? Nutr. J., 13(1):102.

Muthenna, P., G. Raghu, P.A. Kumar, M.V. Surekha, and G.B. Reddy, 2014. Effect of cinnamon and its procyanidin-B2 enriched fraction on diabetic nephropathy in rats. Chem. Biol. Interact. 222c, 68-76.

Ng, S.H and R.W. Wan, 2014. Effect of Cinnamon Powder Addition on Nutritional Composition, Physical Properties and Sensory Acceptability of Butter Biscuits, Malaysian Journal of Nutrition, 245-253.

Qin, B., K.S. Panickar, and R.A. Anderson, 2010a. Cinnamon: potential role in the prevention of insulin resistance, metabolic syndrome, and type 2 diabetes. J. Diabetes Sci. Technol., 4: 685-693.

Qin, B., M.M. Polansky, and R.A. Anderson, 2010b. Cinnamon extract regulates plasma levels of adipose-derived factors and expression of multiple genes related to carbohydrate metabolism and lipogenesis in adipose tissue of fructose-fed rats. Hormone Metab. Res., 42: 187-193.

Ranasinghe, P., S. Pigera, G.A. Premakumara, P. Galappaththy, G.R. Constantine, and P. Katulanda, 2013. Medicinal properties of 'true' cinnamon (Cinnamomum zeylanicum): a systematic review. BMC Complement. Altern. Med., 13, 275.

Rupasinghe, H.P., C.J. Jackson, V. Poysa, C. Di Berardo, J.D. Bewley, and J. Jenkinson, 2003. Soyasapogenol A and B distribution in soybean (Glycine max L. Merr.) in relation to seed physiology, genetic variability, and growing location. J. Agric. Food Chem., 51: 5888-5894.

Saganuwan, A.S., 2010. Some medicinal plants of Arabian Pennisula. J. Med. Plants Res. 4 (9), $767-$ 789.

Sartorius, T., A. Peter, N. Schulz, A. Drescher, I. Bergheim, J. Machann, F. Schick, D. Siegel-Axel, A. Schurmann, C. Weigert, H.U. Haring, and A.M., Hennige, 2014. Cinnamon extract improves insulin sensitivity in the brain and lowers liver fat in mouse models of obesity. PLoS ONE 9, e92358.

Shan, B., Y.Z. Cai, and D.J. Brooks, 2007. Antibacterial properties and major bioactive component of cinnamon stick (Cinnamomum burmannii): activity against food has borne pathogenic bacteria. J. Agric. Food Chem., 55:5484-90.

Sharma, A.K., S. Bharti, R. Kumar, B. Krishnamurthy, J. Bhatia, S. Kumari, and D.S. Arya, 2012. Syzygium cumini ameliorates insulin resistance and beta-cell dysfunction via modulation of PPAR, dyslipidemia, oxidative stress, and TNF-alpha in type 2 diabetic rats. J. Pharmacol. Sci., 119: 205-213.

Vinitha, M. and M. Ballal 2008. In vitro anticandidal activity of Cinnamomum verum. J. Med. Sci., 8: 425-8.

Westenbrink, S., K. Brunt, and J.W. van der Kamp, 2013. Dietary fibre: challenges in production and use of food composition data. Food Chemistry, 140(3): 562-567. 